\title{
Bioinspired Divergent Oxidative Cyclization of Strictosidine and Vincoside Derivatives: Second Generation Enantioselective Total Synthesis of (-)-Cymoside
}

\author{
Yingchao Dou, Cyrille Kouklovsky and Guillaume Vincent* \\ Institut de Chimie Moléculaire et des Matériaux d’Orsay (ICMMO) \\ Université Paris-Saclay, CNRS, 91405, Orsay, France
}

We report our second generation synthesis of (-)-cymoside as well as the formation of a new hexacyclic-fused furo[3,2- $b$ ]indoline framework. After a Pictet-Spengler condensation between secologanin tetraacetate and tryptamine, the course of the cyclization of the 7-hydroxyindolenine intermediate generated by oxidation with an oxaziridine, depends on the stereochemistry of the 3-position. The 3-(S)-strictosidine stereochemistry delivered efficiently the scaffold of cymoside via intramolecular coupling with the C16-C17 enol ether, while the 3-(R)vincoside stereochemistry directed towards the reaction with the $\mathrm{C} 18-\mathrm{C} 19$ terminal alkene and the formation of the unexpected caged compound.

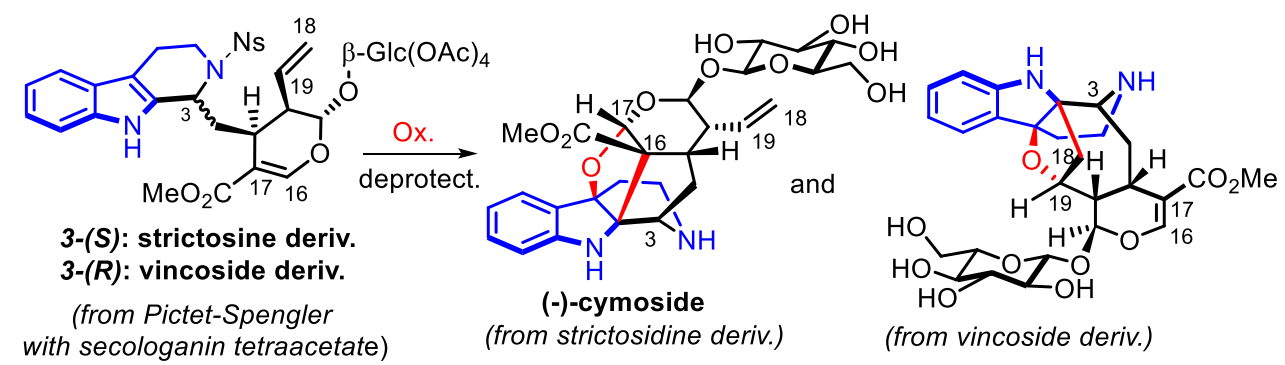

Cymoside (-)-1 is one of the 3000 known monoterpene indole alkaloids ${ }^{1}$ and it possess a highly unusual and intricate structure with a fused-hexacyclic skeleton encompassing a furo[3,2$b$ ]indoline moiety. This natural product was isolated from the tropical tree Chimarrhis cymosa (Rubiaceae) found in Martinique in the French Antilles and its structure was elucidated by Kritsanida, Grougnet and co-workers. ${ }^{2}$

Scheme 1. Biosynthesis of cymoside.
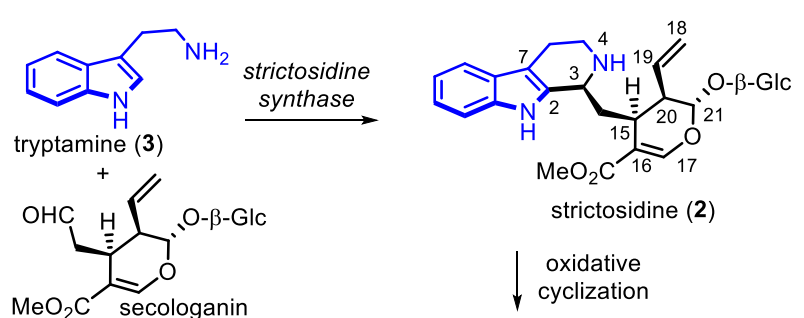

(4)

cymoside (1)

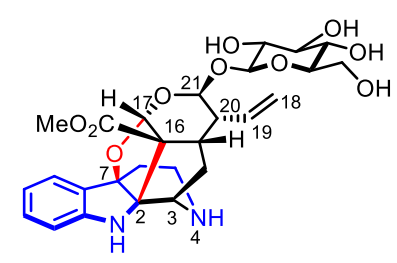

Cymoside biosynthetically arises from a rare direct oxidative cyclization of strictosidine (2), the common biosynthetic precursor of all monoterpene indole alkaloids, which itself has for origin an enzymatic Pictet-Spengler reaction between tryptamine (3) and secologanin (4) (Scheme 1).
In line with our interest in furoindoline moieties ${ }^{3}$ and in the total synthesis of monoterpene indole alkaloids, ${ }^{3 a, 4}$ we recently performed the total synthesis of cymoside $(-)-\mathbf{1}^{5}$ by mimicking the biosynthetic intramolecular oxidative coupling ${ }^{6}$ between the indole nucleus and the enol ether part of the terpenic dihydropyrane to complete the furo[3,2-b]indoline core (Scheme 2). ${ }^{7-9}$ The N-p-nitrophenylsulfonyl ethylether aglycone of racemic strictosidine $( \pm)-6$ was subjected to oxidation with oxaziridine 7 to presumably form 7-hydroxyindoline $\mathbf{A}$ with assistance of the $\mathrm{N}$-sulfonyl group to control the diastereoselectivity. ${ }^{10}$ Subsequent $(3+2)$ annulation proceeds via successive addition of the enol ether to the imine and interception of the incipient oxocarbenium $\mathbf{B}$ by the hydroxy group.

However, this first generation total synthesis suffers from some downsides. We synthesized secologanin aglycon derivative $( \pm)$ 5 in a racemic manner by reproducing the work of Tietze via a Knoevenagel condensation and hetero Diels-Alder cycloaddition sequence. ${ }^{11}$ This aldehyde was engaged in a Pictet-Spengler reaction with tryptamine to deliver strictosidine aglycon derivative ( \pm )-6 with a modest diastereoselectivity. The fact that the key bioinspired cyclization was performed on the racemic aglycon derivative $( \pm)-\mathbf{6 a}$ is the major drawback since only half of this material could lead to the enantiopure natural product. After a low yielding hydrolysis of the acetal part of $( \pm)-\mathbf{8}$, the glycosylation with the enantiopure (D)-glucose derivative 9 was effected on the racemic cymoside aglycon $( \pm)-8$ leading to a mixture of two major $\square$-glucosylated diasteroisomers: cymoside precursor 10a and the coupling product 10b from the 
enantiomeric skeleton of cymoside. Two minor diastereoisomers, resulting from an inefficient stereocontrol at the anomeric positions, were also obtained. Overall, cymoside ()-1 was obtained in a $1.7 \%$ yield from the racemic ethyl ether secologanin aglycone $\mathbf{5}$.

Scheme 2. Our first generation synthesis of cymoside (-)-1 via a racemic synthesis of the cymoside backbone (-)-8.
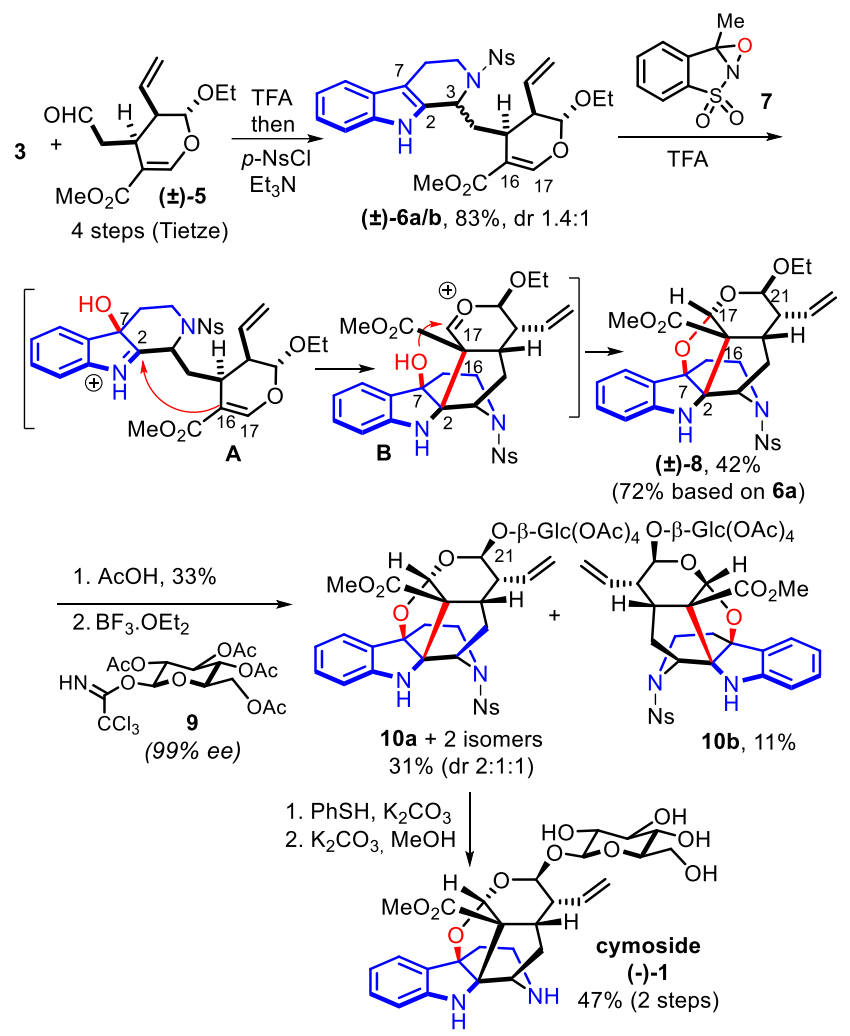

However, this first generation total synthesis suffers from some downsides. We synthesized secologanin aglycon derivative $( \pm)$ 5 in a racemic manner by reproducing the work of Tietze via a Knoevenagel condensation and hetero Diels-Alder cycloaddition sequence. ${ }^{11}$ This aldehyde was engaged in a Pictet-Spengler reaction with tryptamine to deliver strictosidine aglycon derivative ( \pm )-6 with a modest diastereoselectivity. The fact that the key bioinspired cyclization was performed on the racemic aglycon derivative $( \pm)$-6a is the major drawback since only half of this material could lead to the enantiopure natural product. After a low yielding hydrolysis of the acetal part of $( \pm)-\mathbf{8}$, the glycosylation with the enantiopure (D)-glucose derivative 9 was effected on the racemic cymoside aglycon $( \pm)-8$ leading to a mixture of two major $\square$-glucosylated diasteroisomers: cymoside precursor 10a and the coupling product $10 \mathrm{~b}$ from the enantiomeric skeleton of cymoside. Two minor diastereoisomers, resulting from an inefficient stereocontrol at the anomeric positions, were also obtained. Overall, cymoside ()-1 was obtained in a $1.7 \%$ yield from the racemic ethyl ether secologanin aglycone $\mathbf{5}$.

In order to improve the efficiency of the synthesis of cymoside $(-)-\mathbf{1}$, it is, indeed, desirable to effect the bioinspired oxidative cyclization on an enantiopure strictosidine derivative and if possible already containing the $\beta$-(D)-glucose moiety. When we started to study the synthesis of cymoside, no enantioselective syntheses of secologanin (4) or strictosidine (2) were known, despite their pivotal role in the biosynthesis of monoterpene indole alkaloids.

However, at the end of our endeavour, the research group of Ishikawa filled this important gap and reported the first enantioselective synthesis of secologanin (-)-4 (Scheme 3). ${ }^{12}$ The authors cleverly took advantage of an organocatalyzed trans-selective Michael addition developed by Hong of aldehyde 12 onto 1-thioester acrylate 11. ${ }^{13}$ Reduction of the thioester, glycosylation of $\mathbf{1 3}$, hydroboration and sulfoxide elimination delivered secologanin tetraacetate (-)-14 and then secologanin ()-4.

Scheme 3. Synthetic approach towards the enantioselective synthesis of the $(-)$-cymoside backbone.

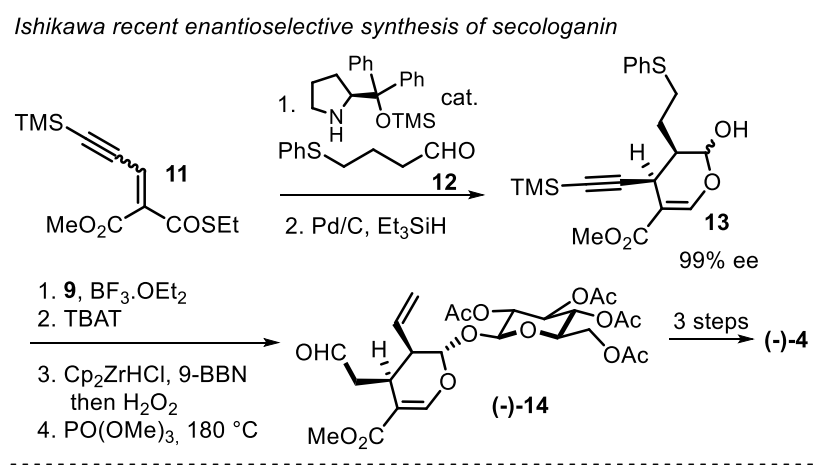

Objective of this work: our second generation synthesis of cymoside
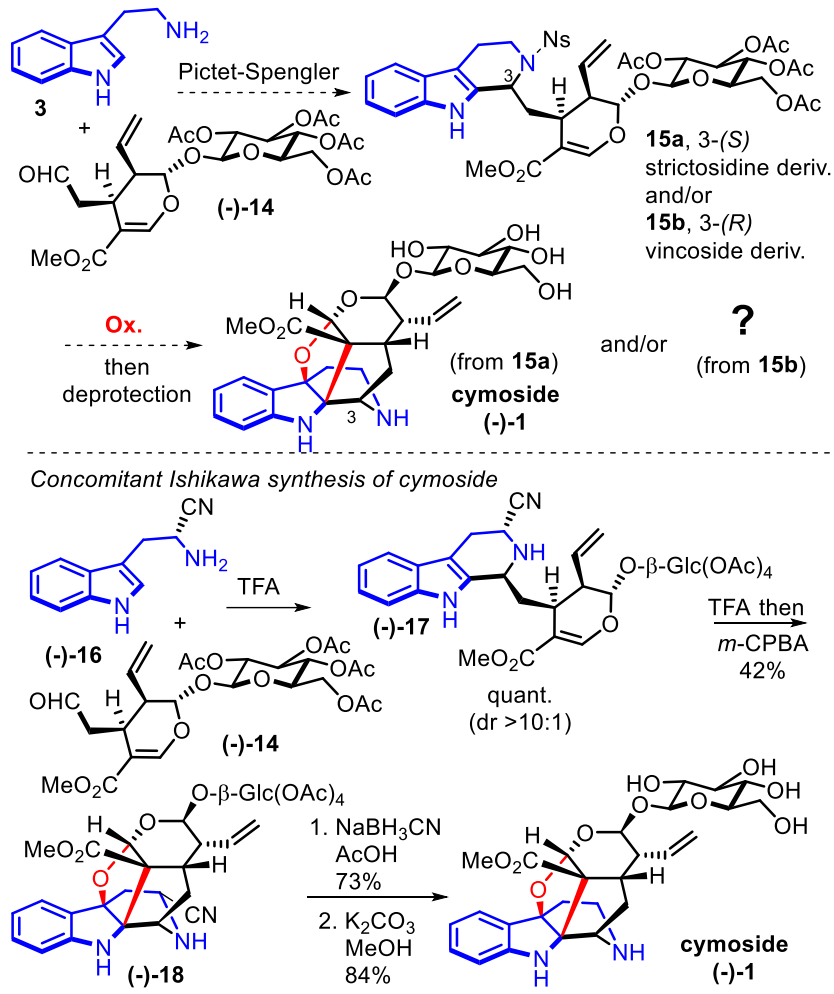

Therefore, after the completion of our first generation synthesis of cymoside (-)-1, it appeared evident to us that using 
enantiopure secologanin tetraacetate $(-)-\mathbf{1 4}$, produced by the Ishikawa enantioselective synthesis, could greatly improve the efficiency of the enantioselective synthesis of cymoside (-)-1 (Scheme 3). Pictet-Spengler reaction with tryptamine should deliver enantiopure protected stritosidine 15a which would be submitted to our biosinspired oxidative cyclization and therefore avoid the low yielding hydrolysis of the acetal and glycosylation steps at a late stage of our first generation synthesis. More importantly, half of the cymoside aglycon would not be lost as it is the case in the racemic approach. In addition, obtaining the C3epimer $\mathbf{1 5 b}$ would also be an opportunity to study its oxidative cyclization.

While we were finishing this second generation synthesis of cymoside (-)-1, Ishikawa published the realization of a similar approach for the total synthesis of cymoside (-)-1 (Scheme 3). ${ }^{14}$ He employed $(R)$ - $\alpha$-cyano tryptamine (-)-16 for the PictetSpengler reaction with (-)-14, in order to ensure a high diastereoselectivity and the oxidative cyclization was performed on protonated strictosidine (-)-17 with $m$-CPBA after prior protonation of the N4 amine. Reduction of the aminonitrile of ()-18 and deacetylation delivered cymoside (-)-1. The very recent publication of Ishikawa urged us to report our own approach herein.

We started our study by the synthesis of secologanin tetraacetate (-)-14 with slight modifications of the Ishikawa procedures (see SI). We then studied the Pictet-Spengler cyclization between tryptamine and secologanin tetraacetate (-)-14 (Scheme 4). ${ }^{15}$ The presence of the glucose moiety on (-)-14 had an impact on the efficiency of the reaction in comparison with aglycon $( \pm)-\mathbf{5}$ since a low conversion was observed with 1.5 equivalent of TFA as in our previous conditions. The tetraacetateglycosyl of (-)-14 offers several chemical functions which could be protonated and thus compete with activation of the imine to induce the PictetSpengler reaction. The reactivity was restored by increasing the amount of TFA to 8 equivalents with an excess of $\mathbf{3}$ and after one-pot nosylation of the N4-secondary amine, a 76\% yield was obtained of a mixture of protected strictosidine 15a and protected vincoside $\mathbf{1 5 b}$, its $\mathrm{C} 3$-epimer in a 1:1.4 ratio in favour of the latter. It is known that a diastereoselective Pictet-Spengler reaction could be performed in presence of the enzyme strictosidine synthase to obtain selectively the stereochemistry of strictosidine. ${ }^{16}$ However this chemoenzymatic approach is not yet easily available to most organic chemistry labs.

Therefore, we envisioned to induce a diastereoselective PictetSpengler reaction with non-racemic chiral catalysts that are known to promote enantioselective Pictet-Spengler reactions. ${ }^{17,18}$ Unfortunately, neither a cinchona-derived thiourea $^{17 \mathrm{~b}, \mathrm{c}}$ nor a squaramide, ${ }^{17 \mathrm{~d}, \mathrm{e}}$ nor a binol-derived phosphoric acid ${ }^{17 f}$ were able to promote the conversion of the reaction. It is probably due to the presence of competitive protonatable functional groups. Mimicking strictosidine synthase with a simple organocatalyst able to induce a highly diastereoselective Pictet-Spengler reaction between tryptamine and secologanin remains a challenge. Ishikawa devised an elegant and efficient alternative by using $\alpha$-cyanotryptamine ()-16 instead of tryptamine (see Scheme 3).
Scheme 4. Divergent oxidative cyclization of $15 \mathrm{a}$ and $15 \mathrm{~b}$ : total synthesis of cymoside (-)-1 and synthesis of (-)-20.
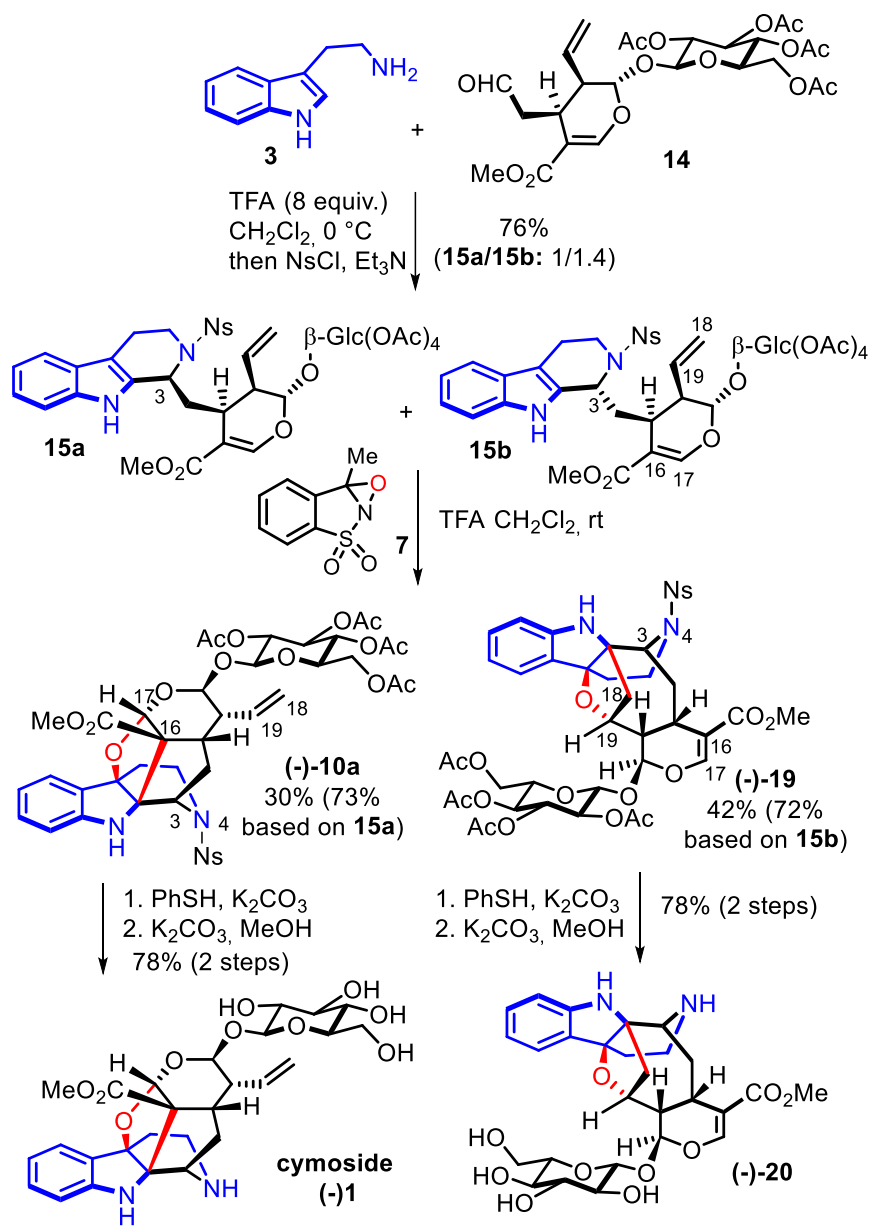

\begin{tabular}{l|l} 
1. $\mathrm{PhSH}, \mathrm{K}_{2} \mathrm{CO}_{3}$ & $\downarrow 78 \%$ (2 steps) \\
2. $\mathrm{K}_{2} \mathrm{CO}_{3}, \mathrm{MeOH}$ &
\end{tabular}

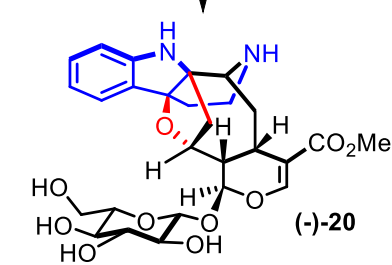

Nevertheless, the latter is synthesized in three steps from tryptophan and the cyano group needs to be removed afterwards. While the diastereoselectivity is not what we expected, this procedure from tryptamine is very straightforward and represents a fast access to protected strictosidine 15a to pursue the total synthesis of cymoside (-)-1. In addition, the access to protected vincoside $\mathbf{1 5 b}$ offered us an opportunity to study its oxidative cyclization.

The 1:1.4 diastereomeric mixture of $\mathbf{1 5} \mathbf{a} / \mathbf{b}$ was then subjected to the oxidative cyclization that we developed with oxaziridine 7 (Scheme 4). ${ }^{5}$ We were delighted to observe that the presence of the glycosyl moiety at this stage did not affect the efficiency of the key bioinspired oxidative cyclization and the furo[3,2$b$ ]indoline-containing hexacyclic fused-skeleton 10a of cymoside was obtained in $30 \%$ yield from the mixture of diastereoisomers which represent a 73\% yield from protected strictosidine 15a. In fact, compound 10a was an intermediate of our first generation total synthesis of cymoside (-)-1, that we intercepted in a much more efficient manner in this second generation approach. We were also thrilled to observe the transformation of protected vincoside $\mathbf{1 5 b}$ into unexpected hexacyclic-fused compound (-)-19 in $42 \%$ yield which represent a $72 \%$ yield from 15b. The intricate furo[3,2- $b]$ indoline- 
containing structure of (-)-19, which was determined by 2D NMR analysis (see SI), is the product of an oxidative cyclization between the indole moiety and the C18-C19 terminal alkene.

In analogy with the formation of the cymoside skeleton (see Scheme 2), we can postulate that the indole moiety is oxidized into 7-hydroxyindolenine $\mathbf{C}$ (Scheme 5). We assume that to minimize steric interactions, the nosyl group blocks the face opposite to the one bearing the monoterpene part at $\mathrm{C} 3$.

Scheme 5. Mechanistic hypothesis for the synthesis of (-)-19.

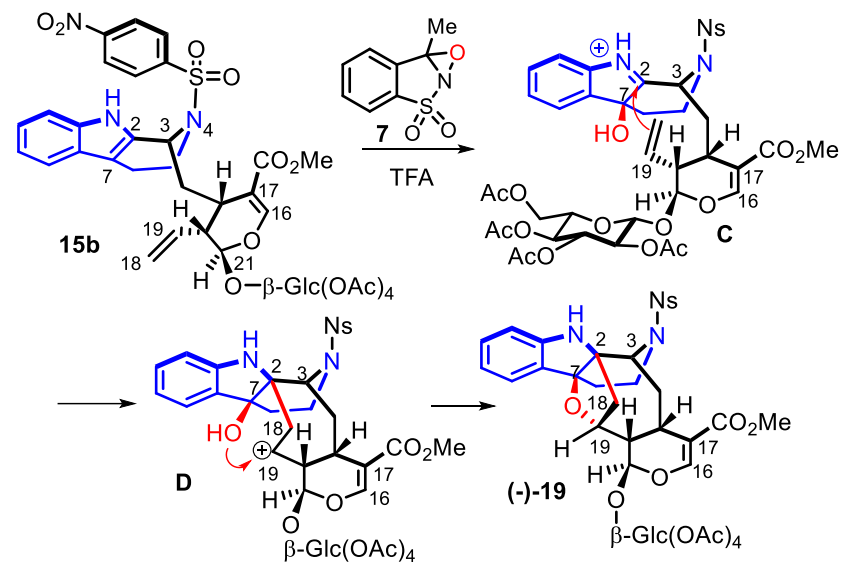

As a result, the oxidation is directed into the latter face which can allow the oxidative cyclization to happen.

In contrast to the formation of the cymoside scaffold $\mathbf{1 0 a}$ from protected strictosidine 15a, the inversion of the configuration at $\mathrm{C} 3$ in vincoside derivative $\mathbf{1 5 b}$ precludes the addition of the enol part to the C2-position. Alternatively, the terminal position of the C18-C19 alkene is poised to add onto the C2-iminium of $\mathbf{C}$ leading to the formation of the seven-membered ring of tertiary carbocation D. The latter would then be intercepted by the hydroxyl group at $\mathrm{C} 7$ to complete the synthesis of the fivemembered ring of the furo[3,2-b]indoline moiety of (-)-19.

All what remained, was to achieve the two deprotection steps (Scheme 4). Attempts to effect this double deprotection in the same pot did not succeeded, therefore it was performed uneventfully in two steps. The nosyl group was removed from the secondary amine with thiophenol in presence of potassium carbonate and in a second operation the four acetyl groups were removed from the glucose moiety with potassium carbonate in methanol to finally deliver cymoside (-)-1 in $78 \%$ yield. All spectra data of this synthetic cymoside (-)-1 were in strong agreement with the ones of the natural substance as well as the synthetic products of our first generation synthesis as well as the Ishikawa synthesis. ${ }^{19,20}$

The same deprotective sequence of two steps was also applied to (-)-19 to deliver (-)-20. Worthy of note, we did not observe any lactamisation between the methyl ester at C16 and the N4secondary amine after the removal of the nosyl group in basic conditions.

While the unique structure of (-)-20 is not presently known among natural products, it is not unconceivable that it could be produced by Nature via an oxidative cyclization related to the one that we have uncovered (Scheme 5). Indeed, unlike (-)-20, most of the monoterpene indole alkaloids possess a $(S)$ - configuration at the 3 position arising from strictosidine. However, there are few examples of monoterpene indole alkaloids that display a $(R)$-configuration at this position such as vincosamide or reserpine.

\section{Conclusions}

We significantly improved the synthesis of cymoside (-)-1 that we published earlier this year by starting from enantiopure secologanin tetraacetate instead of its racemic aglycon. After the Pictet-Spengler reaction, the key bioinspired oxidative cyclization of strictosidine derivative $15 \mathbf{a}$ between the indole and the $\mathrm{C} 16-\mathrm{C} 17$ enol ether proceeded well in presence of the glucose moiety. Cymoside (-)-1 was synthesized in 4 steps and $18 \%$ yields from secologanin tetraacetate $\mathbf{1 4}$ obtained according to the synthesis of Ishikawa, while our first generation synthesis required 6 steps and $1.7 \%$ yields from racemic secologanin aglycon $( \pm)-5$. It has been realized in parallel and concomitantly with the work of Ishikawa who obtained cymoside (-)-1 via a very similar strategy. In a divergent manner, the oxidation of the vincoside derivative $\mathbf{1 5} \mathbf{b}$, the 3 -epimer of $\mathbf{1 5 a}$, yielded a new fused hexacyclic furo[3,2-b]indoline structure $\mathbf{2 0}$ via reaction with the terminal C18-C19 alkene instead of the C16-C17 enol ether. It was obtained in 4 steps and $25 \%$ yields from secologanin tetraacetate $\mathbf{1 4}$

\section{Acknowledgements}

YD thanks the China Scholarship Council (CSC) for his PhD fellowship. We also gratefully acknowledge the ANR (ANR-15CE29-0001; "Mount Indole"), the Université Paris-Saclay and the CNRS for financial support. We would like to thank Dr. Marina Kritsanida and Dr. Raphaël Grougnet from the Faculty of Pharmacy of Université Paris-Descartes for fid data of all NMR of natural cymoside and helpful discussions as well as Dr. Laurent Evanno and Prof. Erwan Poupon from the Faculty of Pharmacy of Université Paris-Saclay for helpful discussions.

\section{References}

1 For reviews on monoterpene indole alkaloids: (a) S. E. O'Connor and J. J. Maresh, Nat. Prod. Rep., 2006, 23, 532547; (b) L. F. Szabó, Molecules, 2008, 13, 1875-1896.

2 C. Lémus, M. Kritsanida, A. Canet, G. Genta-Jouve, S. Michel, B. Deguin and R. Grougnet, Tetrahedron Lett., 2015, 56, 5377-5380.

3 (a) D. Lachkar, N. Denizot, G. Bernadat, K. Ahamada, M. A. Beniddir, V. Dumontet, J.-F. Gallard, R. Guillot, K. Leblanc, E. O. N'nang, V. Turpin, C. Kouklovsky, E. Poupon, L. Evanno and G. Vincent, Nat. Chem., 2017, 9, 793-79; (b) A.S. Marques, V. Coeffard, I. Chataigner, G. Vincent and X. Moreau, Org. Lett., 2016, 18, 5296-5299; (c) T. Tomakinian, R. Guillot, C. Kouklovsky and G. Vincent, Chem. Commun., 2016, 52, 5443-5446; (d) T. Tomakinian, R. Guillot, C. Kouklovsky and G. Vincent, Angew. Chem. Int. Ed., 2014, 53, 11881-11885; (e) N. Denizot, A. Pouilhès, M. Cucca, R. Beaud, R. Guillot, C. Kouklovsky and G. Vincent, Org. Lett., 2014, 16, 5752-5755; (f) R. Beaud, R. Guillot, C. Kouklovsky and G. Vincent, Angew. Chem., 2012, 124, 12714-12718. 
4 (a) M. Jarret, A. Tap, C. Kouklovsky, E. Poupon, L. Evanno and G. Vincent, Angew. Chem. Int. Ed., 2018, 57, 1229412298; (b) M. Jarret, V. Turpin, A. Tap, J.-F. Gallard, C. Kouklovsky, E. Poupon, G. Vincent and L. Evanno, Angew. Chem. Int. Ed., 2019, 58, 9861-9865.

5 Y. Dou, C. Kouklovsky, V. Gandon and G. Vincent, Angew. Chem. Int. Ed., 2020, 59, 1527-1531.

6 For a review on total syntheses of indole alkaloids involving an oxidative coupling: K. Nagaraju and D. Ma, Chem. Soc Rev., 2018, 47, 8018-8029.

7 Selected methods for the synthesis of furo[3,2-b]indoline derivatives: (a) A. Bonderoff and A. Padwa, Org. Lett., 2013, 15, 4114-4117; (b) Y. Tokimizu, S. Oishi, N. Fujii and H. Ohno, Angew. Chem. Int. Ed., 2015, 54, 7862-7866; (c) A. Morris, T. H. Nguyen and N. Zheng, Adv. Synth. Catal., 2015 , 357, 2311-2316; (d) E. Deruer and S. Canesi, Org. Biomol. Chem., 2017, 15, 3736-3741; (e) Z. Xia, J. Hu, Y.-Q. Gao, Q. Yao and W. Xie, Chem. Commun., 2017, 53, 7485-7488.

8 Total syntheses of phalarine which possess a related benzofuro[3,2-b]indoline motif: (a) C. Li, C. Chan, A. C. Heimann and S. J. Danishefsky, Angew. Chem. Int. Ed., 2007, 46, 1444-1447; (b) J. D. Trzupek, D. Lee, B. M. Crowley, V. M. Marathias and S. J. Danishefsky, J. Am. Chem. Soc., 2010, 132, 8506-8512; (c) H. Ding and D. Y.-K. Chen, Angew. Chem. Int. Ed., 2011, 50, 676-679; (d) L. Li, K. Yuan, Q. Jia and Y. Jia, Angew. Chem. Int. Ed., 2019, 58, 6074-6078; synthetic studies towards benzofuro[3,2-b]indolines: (e) K Muñiz, J. Am. Chem. Soc., 2007, 129, 14542-14543; (f) S. S K. Boominathan and J.-J. Wang, Chem. - Eur. J., 2015, 21, 17044-17050; (g) K. Douki, J. Shimokawa and M. Kitamura, Org. Biomol. Chem., 2019, 17, 1727-1730.

9 Total syntheses of lapidilectine B and grandilodine C which possess a related furo[3,2- $b$ ]indolone motif: (a) W. H. Pearson, Y. Mi, I. Y. Lee and P. Stoy, J. Am. Chem. Soc., 2001, 123, 6724-6725; (b) M. Nakajima, S. Arai and A. Nishida, Angew. Chem. Int. Ed., 2016, 55, 3473-3476; (c) Y. Gao, M. Fan, Q. Geng and D. Ma, Chem. - Eur. J., 2018, 24, 6547-6550; (d) F. M. Miloserdov, M. S. Kirillova, M. E. Muratore and A. M. Echavarren, J. Am. Chem. Soc., 2018, 140, 5393-5400; synthetic studies towards furo[3,2-b]indolones: (e) M. Ikeda, T. Uno, K.-I. Homma, K. Ohno and Y. Tamura, Synth. Commun., 1980, 10, 437-449; (f) T. Izumi, K. Kohei and S Murakami, J. Heterocycl. Chem., 1993, 30, 1133-1136; (g) T. Kawasaki, K. Masuda, Y. Baba, R. Terashima, K. Takada and M. Sakamoto, J. Chem. Soc. Perkin 1, 1996, 729-733; (h) V. Ramella, Z. He, C. G. Daniliuc and A. Studer, Eur. J. Org. Chem., 2016, 2268-2273.

10 Synthesis of hydroxyindolenine intermediates via oxidation of indoles in the context of total synthesis: (a) R. M. Williams, T. Glinka and E. Kwast, J. Am. Chem. Soc., 1988, 110, 59275929; (b) S. Liu, J. S. Scotti and S. A. Kozmin, J. Org. Chem., 2013, 78, 8645-8654; (c) E. V. Mercado-Marin, P. GarciaReynaga, S. Romminger, E. F. Pimenta, D. K. Romney, M. W. Lodewyk, D. E. Williams, R. J. Andersen, S. J. Miller, D. J. Tantillo, R. G. S. Berlinck and R. Sarpong, Nature, 2014, 509, 318-324; (e) Y. Sun, P. Chen, D. Zhang, M. Baunach, C. Hertweck and A. Li, Angew. Chem. Int. Ed., 2014, 53, 9012 9016; (f) C. Piemontesi, Q. Wang and J. Zhu, Angew. Chem. Int. Ed., 2016, 55, 6556-6560; (g) R. C. Godfrey, N. J. Green, G. S. Nichol and A. L. Lawrence, Nat. Chem., DOI: $10.1038 / \mathrm{s} 41557-020-0442-3$.

11 L. F. Tietze, H. Meier and H. Nutt, Liebigs Ann. Chem., 1990, 253-260.

12 K. Rakumitsu, J. Sakamoto and H. Ishikawa, Chem. - Eur. J., 2019, 25, 8996-9000.

13 B.-C. Hong, N. S. Dange, P.-J. Yen, G.-H. Lee and J.-H. Liao, Org. Lett., 2012, 14, 5346-5349.
14 H. Ishikawa, J. Sakamoto, Y. Umeda, K. Rakumitsu and M. Sumimoto, Angew. Chem. Int. Ed. DOI:10.1002/anie.202005748.

15 Á. Patthy-Lukáts, Á. Kocsis, L. F. Szabó and B. Podányi, J. Nat. Prod., 1999, 62, 1492-1499.

16 Selected examples: (a) U. Pfitzner and M. H. Zenk, Planto Med., 1982, 46, 10-14; (b) H.-B. Zou, H.-J. Zhu, L. Zhang, L.Q. Yang, Y.-P. Yu and J. Stöckigt, Chem. - Asian J., 2010, 5, 2400-2404; (c) P. Bernhardt, A. R. Usera and S. E. O'Connor, Tetrahedron Lett., 2010, 51, 4400-4402; (d) D. Pressnitz, E.M. Fischereder, J. Pletz, C. Kofler, L. Hammerer, K. Hiebler, H. Lechner, N. Richter, E. Eger and W. Kroutil, Angew. Chem. Int. Ed., 2018, 57, 10683-10687.

17 For a review: a) N. Glinsky-Olivier and X. Guinchard, Synthesis, 2017, 49, 2605-2620; for selected examples: (b) R. S. Klausen and E. N. Jacobsen, Org. Lett., 2009, 11, 887-890; (c) I. P. Kerschgens, E. Claveau, M. J. Wanner, S. Ingemann, J. H. van Maarseveen and H. Hiemstra, Chem. Commun., 2012, 48, 12243-12245; (d) S. M. Banik, A. Levina, A. M. Hyde and E. N. Jacobsen, Science, 2017, 358, 761-764; (e) L. Qi, H. Hou, F. Ling and W. Zhong, Org. Biomol. Chem., 2018, 16, 566-574; (f) J. Seayad, A. M. Seayad and B. List, J. Am. Chem. Soc., 2006, 128, 1086-1087.

18 The following catalysts were evaluated without success:

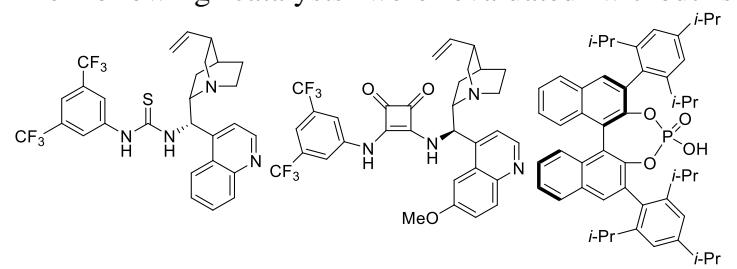

19 The optical rotation of the product obtained in this second generation synthesis $\left(\left([\alpha]^{\mathrm{D}}-29.5 \mathrm{c} 0.475\right.\right.$ in $\left.\mathrm{MeOH}\right)$ is also similar to the ones of our first generation $\left([\alpha]^{\mathrm{D}}-26.3\right.$, c 0.015 in $\mathrm{MeOH})^{5}$ and the Ishikawa $\left([\alpha]^{\mathrm{D}}-28.9 \text {, c } 0.3 \text { in } \mathrm{MeOH}\right)^{14}$ syntheses. These three values significantly differ from the optical rotation reported in the isolation paper $\left([\alpha]^{\mathrm{D}}+190, \mathrm{c}\right.$ 0.011 in $\mathrm{MeOH})^{2}$ which we believe is not accurate.

20 Slight differences of the ${ }^{1} \mathrm{H}$ and ${ }^{13} \mathrm{C}$ signals at positions in proximity of the N4 secondary amine were observed (see SI). It could be explained by the fact that this $\mathrm{N} 4$ secondary amine could be involved in hydrogen bonding interactions. 